\title{
An enhanced control strategy based imaginary swapping instant for induction motor drives
}

\author{
Iliass Rkik, Mohamed El khayat, Abdelali Ed-Dahhak, Mohammed Guerbaoui, Abdeslam Lachhab \\ Department of Electrical Engineering, Modelling, Materials and Systems Control Team, Higher School of Technology, Moulay Ismail \\ University, Meknes, Morocco
}

\begin{tabular}{l}
\hline \hline Article Info \\
\hline Article history: \\
Received Feb 5, 2021 \\
Revised Sep 11, 2021 \\
Accepted Oct 8, 2021 \\
\hline
\end{tabular}

\section{Keywords:}

Direct torque control Imaginary swapping instant Improved DTC-SVM Induction motor control Torque ripples

\begin{abstract}
The main aim of this paper is to present a novel control approach of an induction machine (IM) using an improved space vector modulation based direct torque control (SVM-DTC) on the basis of imaginary swapping instant technique. The improved control strategy is presented to surmount the drawbacks of the classical direct torque control (DTC) and to enhance the dynamic performance of the induction motor. This method requires neither angle identification nor sector determination; the imaginary swapping instant vector is used to fix the effective period in which the power is transferred to the IM. Both the classical DTC method and the suggested adaptive DTC techniques have been carried out in MATLAB/Simulink ${ }^{T M}$. Simulation results shows the effectiveness of the enhanced control strategy and demonstrate that torque and flux ripples are massively diminished compared to the conventional DTC (CDTC) which gives a better performance. Finally, the system will also be tested for its robustness against variations in the IM parameters.
\end{abstract}

This is an open access article under the CC BY-SA license.

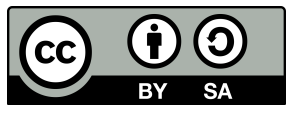

\section{Corresponding Author:}

Iliass Rkik

Department of Electrical Engineering, System's Modeling, Materials, and Control group, Ecole Superieure de Technologie de Meknes (ESTM), Moulay Ismail University

ESTM Km 5, Avenue d'Aggouray, P1, Meknes 50000, Morocco

Email: iliass.rkik@edu.umi.ac.ma, rkik.iliass@gmail.com

\section{INTRODUCTION}

In the last decade, a peak of $68-70 \%$ of the total energy provided to the industry is absorbed by electric motors. In addition, sensorless induction motor drive control has aquired an extensive attention in the industrial applications [1], this is because of the different benefits of the induction machine (IM) essentially, reduced repairs, obvious and robust architecture [2], [3].

Generally, the most methods commonly used to drive the induction motor are scalar control (V/F), direct torque control (DTC) and field oriented control (FOC) [4]. The direct torque and flux control were introduced in 1986 in order to surmount the problems of the antecedent traditional control techniques. Moreover, the basic principle operation of the traditional DTC is the regulation of the torque and flux errors through two hysteresis comparators. The classical DTC technique is distinguished by its high dynamic performance and durability. However, the hysteresis controllers generate undesired ripples in torque and flux response which directly cause a disagreeable acoustic noise and provoke mechanical vibrations [5], [6]. Different studies have established a significant improvement to the conventional DTC (CDTC) in order to surmount the CDTC drawbacks [7]. DTC with space vector modulation strategy (DTC-SVM) is one of the techniques used to enhance the CDTC [8]. In [9], an improved DTC technique dedicated to B6-Inverter with 2 phase IM drive, consider- 
ing a bus clamping strategy in combination with the vector selection table. Moreover, low ripples can also be supported by the multilevel converters [10], [11]. An improved approach is presented using five-level cascaded H-bridge (CHB) inverters based DTC control drive in order to reduce torque ripples. In addition, an efficient DTC control strategy based on adaptive artificial neural network (ANN) for electrical motor was presented in [12], [13]. An optimized strategy based on fuzzy logic controller was performed in [14]. The model predictive strategy has a part in the literature in many areas of research and development [15]-[17]. In this context, this paper mainly focuses on a novel advanced DTC-SVM based on the concept of imaginary swapping instants in order to dismiss the significant drawbacks of the CDTC, which are vibrations and acoustics noise due to high torque ripples [18].

\section{SYSTEM MODELING AND STRUCTURE}

The basic architecture of the control system [19] is presented in Figure 1. It consists of an induction motor pursuant to the proposed SVM-DTC method powered by a VSI and a centrifugal pump as a load. The parameter of the used induction motor are shown in the Table 1.

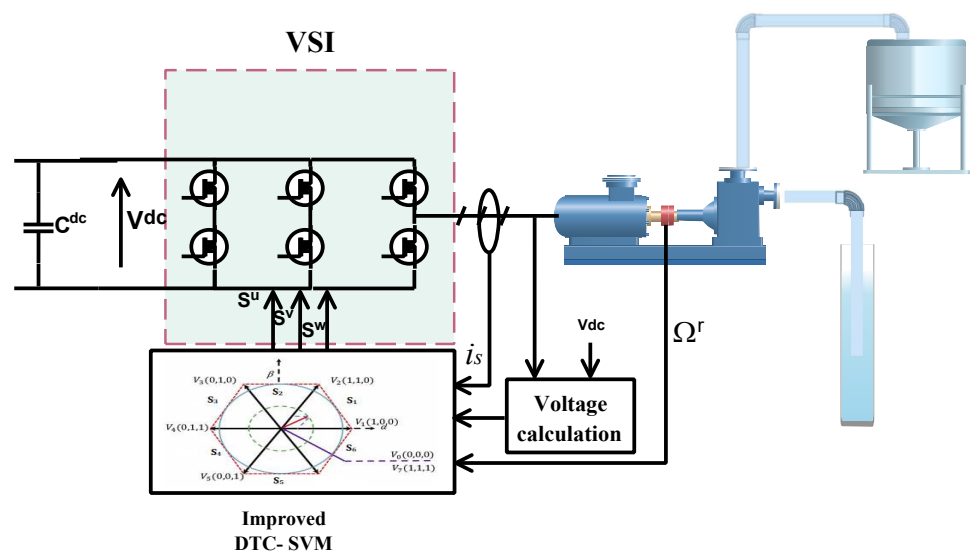

Figure 1. The system's architecture

Table 1. Induction motor parameters

\begin{tabular}{cc}
\hline Variable & Value \\
\hline Rated power P [Kw] & 1500 \\
Rated line voltage [V] & $220 / 380$ \\
Rated seed [RPM] & 1435 \\
Stator and rotor resistance $[\Omega]$ & {$[4,82-4,82]$} \\
Stator and rotor inductances $[\mathrm{H}]$ & {$[0,195-0,195]$} \\
Moment of inertia $J_{m n}\left[\mathrm{Kg} \cdot \mathrm{m}^{2}\right]$ & 0.0171 \\
Pole pairs P & 2 \\
\hline
\end{tabular}

\subsection{IM modeling}

The mathematical model of three-phases IM [20], [21] is given in two-dimensional reference frame d-q by (1):

$$
\left\{\begin{array}{l}
V_{s, d}=R_{s} I_{s, d}+\frac{d \psi_{s, d}}{d t} \\
V_{s, q}=R_{s} I_{s, q}+\frac{d \psi_{s, q}}{d t} \\
V_{r, d}=0=R_{r} I_{r, d}+\frac{d \psi_{s, d}}{d t}+\frac{d \theta}{d t} \psi_{r, d} \\
V_{r, q}=0=R_{r} I_{r, q}+\frac{d \psi_{s, q}}{d t}+\frac{d \theta}{d t} \psi_{r, q}
\end{array}\right.
$$

as shown in (2), the electromagnetic torque $T_{e}$ of the three-phase induction motor is expressed as (2):

$$
T_{e}=\frac{3 P}{4} \frac{L_{m}}{L^{\prime} L_{r} L_{s}}\left|\psi_{s}\right|\left|\psi_{r}\right| \sin \left(\theta_{\psi}\right)
$$


where, $\mathrm{P}$ is the number of poles, $\theta_{\psi}$ is the angle between the stator flux vector and rotor flux vector, $\mathrm{Ls}, \mathrm{Lr}, \mathrm{Lm}$ are mutual inductances for both stator and rotor, $L^{\prime}=1-\left(\frac{L_{m}^{2}}{L_{s} L_{r}}\right)$ is Blondel's leakage factor [22], $\left(\psi_{s}, \psi_{r}\right)$ are the stator and rotor flux. Thus, from the (2) we can deduce that the control of the expressed electromagnetic torque depends into the rate of change of $\theta_{\psi}$. The following formula (3) presents the reference stator flux vector as polar to rectangular conversion [23]. Where $\theta_{r}$ present rotor flux angle.

$$
\psi_{s}^{*}=\left|\psi_{s}^{*}\right| \cos \left(\gamma+\theta_{r}\right)+j\left|\psi_{s}^{*}\right| \sin \left(\gamma+\left[\theta_{r}\right]\right)
$$

\section{CONTROL METHODOLOGIES FOR THE STUDIED SYSTEM}

The control of the induction motors is crucial with a view to ensure the precision and optimum performance of the system [24]. The following section describes the proposed controller for the induction motors.

\subsection{Principle of classical DTC control}

In conventional DTC, the basic working principle of operation of this technique is flux and torque errors through two hysteresis comparators. Moreover, traditional DTC drive is based on voltage source inverter (VSI) with two zero voltage vectors $\left(V_{z 0}\right.$ and $\left.V_{z 7}\right)$ and six nonzero voltage vectors $\left(V_{1}, V_{2} \ldots V_{6}\right)$ [25]. The optimum choice of vectors is effected via a switching table. The switching table is made on the basis of torque error and the stator flux vector position, the schematic representation of the classical DTC is presented in Figure 2. The fundamental concept of the suggested method is to use the switching instant strategy to generate the required voltage vector with the purpose of minimizing the amount of torque ripples in the induction machine.

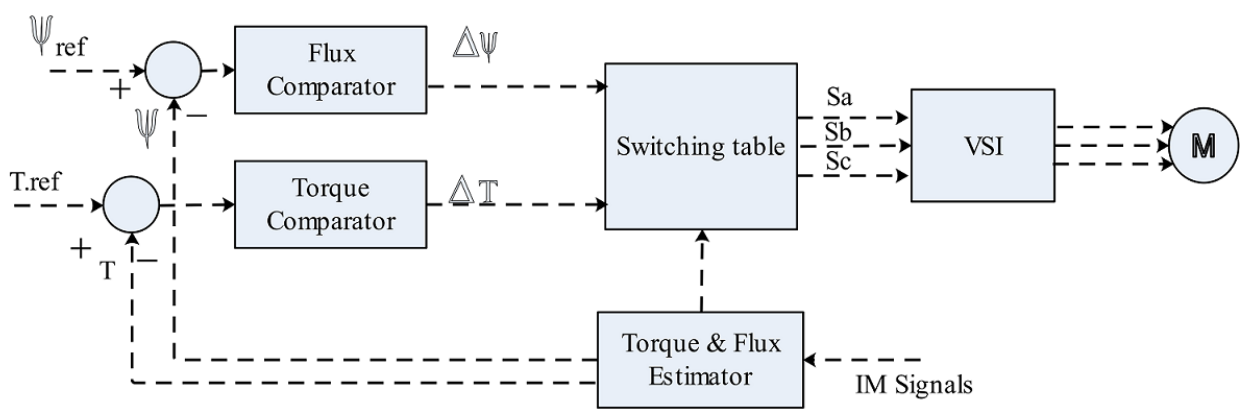

Figure 2. General diagram of classical-DTC based hysteresis technique

\subsection{Imaginary switching instant concept}

The modulating voltages functions of three phase inverter are often sinusoidal, thus represent a revolving space vector Vs. Vs is located in one sector from the hexagon switching vector diagram as presented in Figure 3(a), Vs is constructed by the adjacent of the nearest voltage vectors $\mathrm{V}^{\prime}{ }_{n}(\mathrm{k})$ and $\mathrm{V}_{n}{ }_{n}(\mathrm{k}+1)$ and the null vectors $\mathrm{V}_{0}$ or $\mathrm{V}_{7}$ for a specified period in any sequence, as shown in the Figure $3(\mathrm{~b})$. Vs is resolved by the following analysis:

$$
\begin{gathered}
V_{S} * \sin \left(\frac{\pi}{3}-\gamma\right)=V_{r}^{\prime} * \sin \frac{\pi}{3} \\
V_{s} * \sin (\gamma)=V_{r}^{\prime} * \sin \frac{\pi}{3}
\end{gathered}
$$

$\mathrm{Vs}$ is located in the first sector, so we get:

$$
\begin{gathered}
V_{s}=V_{k}^{\prime}+V_{k+1}^{\prime}+V_{0} \text { or } V_{7} \\
V_{s}=V_{r}^{\prime}+V_{l}^{\prime}=V_{1}^{\prime} \frac{T_{1}}{T_{s p}}+V_{2}^{\prime} \frac{T_{2}}{T_{s p}}+\left(V_{0} \text { or } V_{7}\right) \frac{T_{0}}{T_{s p}}
\end{gathered}
$$




$$
\text { Or, } \quad V_{s} T_{s p}=V_{1}^{\prime} T_{1}+V_{1}^{\prime} T_{1}
$$

where, $V_{r}^{\prime}$ and $V_{l}^{\prime}$ are the adjacent component of $V_{s}$ in the same orientation of $V_{1}^{\prime}$ and $V_{2}^{\prime} . T_{s p}$ is the sampling time period, $T_{2}, T_{0}$ and $T_{1}$ are the time periods for which $\left(V_{1}^{\prime}, V_{2}^{\prime}\right.$ and $\left.V_{0}^{\prime}\right)$ are enforced, with $\left(V_{1}^{\prime}=V_{2}^{\prime}=\right.$ $\left.\frac{2}{3} V_{D C}\right)$.

$$
\left\{\begin{array}{l}
T_{1}=T_{s p} \cdot C_{v} \cdot \sin \left(\frac{\pi}{3}-\gamma\right) \frac{2}{\sqrt{3}} \\
T_{2}=T_{s p} \cdot C_{v} \cdot \sin (\gamma) \frac{2}{\sqrt{3}}
\end{array}\right.
$$

Where $\gamma$ is the angle between Vs and d-axis, with $C_{v}=\left(\frac{V_{S}}{V_{1}^{\prime}}\right)=\left(\frac{V_{S}}{V_{2}^{\prime}}\right)$. The simplification of (8) in terms of instantaneous phases gives the following results:

$$
\begin{gathered}
T_{1}=\frac{V_{a s}^{\prime}}{V_{D C}} T_{s p}-\frac{V_{b s}^{\prime}}{V_{D C}} T_{s p} \\
T_{2}=\frac{V_{b s}^{\prime}}{V_{D C}} T_{s p}-\frac{V_{c s}^{\prime}}{V_{D C}} T_{s p} \\
\left\{\begin{array}{l}
T_{1}=T_{s u}-T_{s v} \\
T_{2}=T_{s v}-T_{s w}
\end{array}\right. \\
T_{s u}=\frac{V_{a s}^{\prime}}{V_{D C}} T_{s p}, T_{s v}=\frac{V_{b s}^{\prime}}{V_{D C}} T_{s p} \& T_{s w}=\frac{V_{c s}^{\prime}}{V_{D C}} T_{s p}
\end{gathered}
$$

Thus the active vectors swapping instant $\mathrm{T} 1$ or $\mathrm{T} 2$ can be represented by the imaginary times $T_{s u}, T_{s v}$ and $T_{s w}$. These times depends automatically on the stator reference voltages.

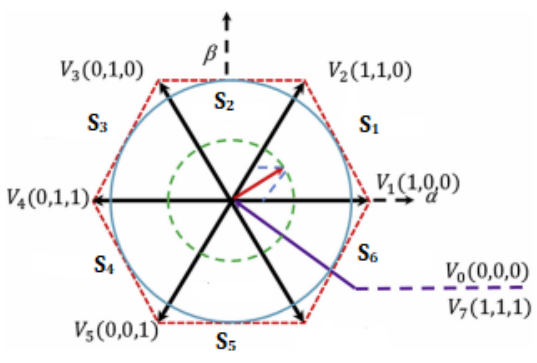

(a)

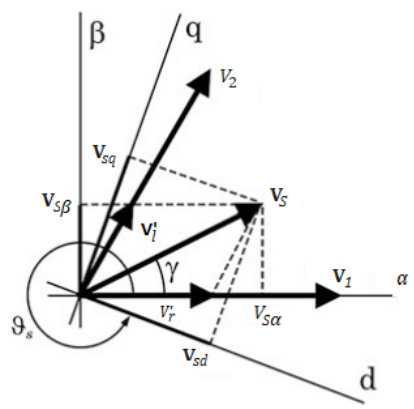

(b)

Figure 3. Representation of the voltage space vector location in (a) hexagon sector vector diagram and (b) construction of $\mathrm{Vs}$

\subsection{Proposed DTC strategy based imaginary swapping instant}

The sum of slip velocity and real motor speed is the synchronous velocity of the reference flux vectors. The real stator flux space vectors and the electromagnetic torque in a d-q-frame can be generated by the measurement of any two-phase currents and voltages from the IM itself. The flux vector's angle is achieved by integrating the synchronous speed. Besides, the imaginary switching instant is extracted from the error between estimated and reference flux. Therefore, the improved strategy of control requires neither the switching table sectors determination, nor angle identification which gives the processor more agility and provide the best way-out. The following equations calculate the d-q component of the imaginary swapping time:

The stator resistance $R_{s}$ is too small, so it can be neglected in the analysis.

$$
V_{s}=\left[R_{s}\right] i_{s}+\frac{d \psi_{s}}{d t}
$$




$$
\begin{gathered}
\Delta \psi_{s}=V_{s} \cdot \Delta t \\
\Delta \psi_{s, d}+j \Delta \psi_{s, q}=V_{s, d}+j V_{s, q}
\end{gathered}
$$

Taking the imaginary and real constituents of (11) and (12) gives:

$$
V_{s, d}=\frac{\Delta \psi_{s, d}}{\Delta t}=\frac{\psi_{s, \mathrm{~d}}^{*}-\psi_{s, d}}{\Delta t} \quad \text { and } \quad V_{s, q}=\frac{\Delta \psi_{s, q}}{\Delta t}=\frac{\psi_{s, q}^{*}-\psi_{s, q}}{\Delta t}
$$

where, $\Delta t$ is equal to the sampling time $T_{s p}$. Hence, in (13) present the calculation of the imaginary swapping instant in d-q stationary axis frame based on the calculus of (9).

$$
\begin{aligned}
& T_{s d}=\frac{V_{s, d}}{V_{D C}} T_{s p}=\frac{\Delta \psi_{s, d}}{\Delta t \times V_{D C}} T_{s p}=\frac{\psi_{s, d}^{*}-\psi_{s, d}}{V_{D C}} \\
& T_{s q}=\frac{V_{s, q}}{V_{D C}} T_{s p}=\frac{\Delta \psi_{s, q}}{\Delta t \times V_{D C}} T_{s p}=\frac{\psi_{s, q}^{*}-\psi_{s, q}}{V_{D C}}
\end{aligned}
$$

Or,

$$
T_{s}=T_{s d}+j T_{s q}
$$

Therefore:

$$
T_{s}=\frac{V_{s}}{V_{D C}} T_{s}=\frac{\psi_{s}^{*}-\psi_{s}}{V_{D C}}
$$

Hence a novel definition of the imaginary instant vector is presented by (17), which explicitly determines the defined swapping instants of the voltage source inverter (VSI). The imaginary swapping times are reached by transforming the imaginary vector time components from two to three phases [26]. The schematic design of the improved DTC-SVM approach is represented in the Figure 4.

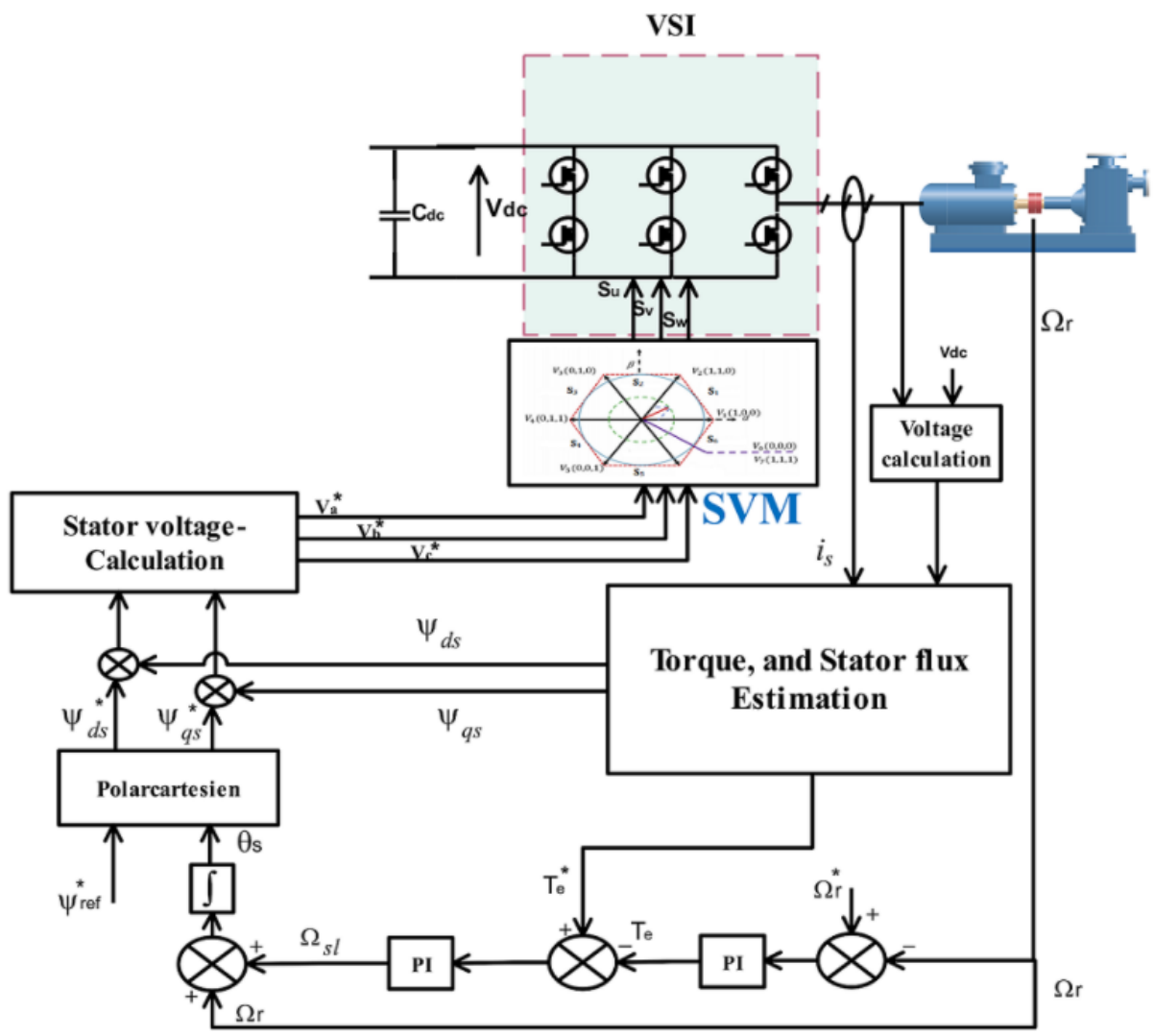

Figure 4. Schematic diagram of the improved-DTC technique 


\section{SIMULATION TEST AND ANALYSIS}

Using MATLAB/Simulink ${ }^{T M}$ environment, the simulations have been performed for both CDTC and the improved DTC-SVM technique to analyze the effectiveness of the developed technique. The simulation is conducted by a three-phase $1.5 \mathrm{~kW}$ induction motor. To improve the effectiveness of the enhanced technique, two test class were carried out, which are load torque change sensitivity and robustness. Firstly, the implication of simulation shows the comparative study of the improved and the conventional techniques with a variation of load torque. As shown in the figures below, the induction motor can be inspected with high performance. Figures 5 and 6 illustrate the steady state performance of the three phase stator currents of both CDTC and the developed DTC-SVM, it can be observed that the enhanced control technique has the best sinusoid waveform and gives a better performance compared to the CDTC.

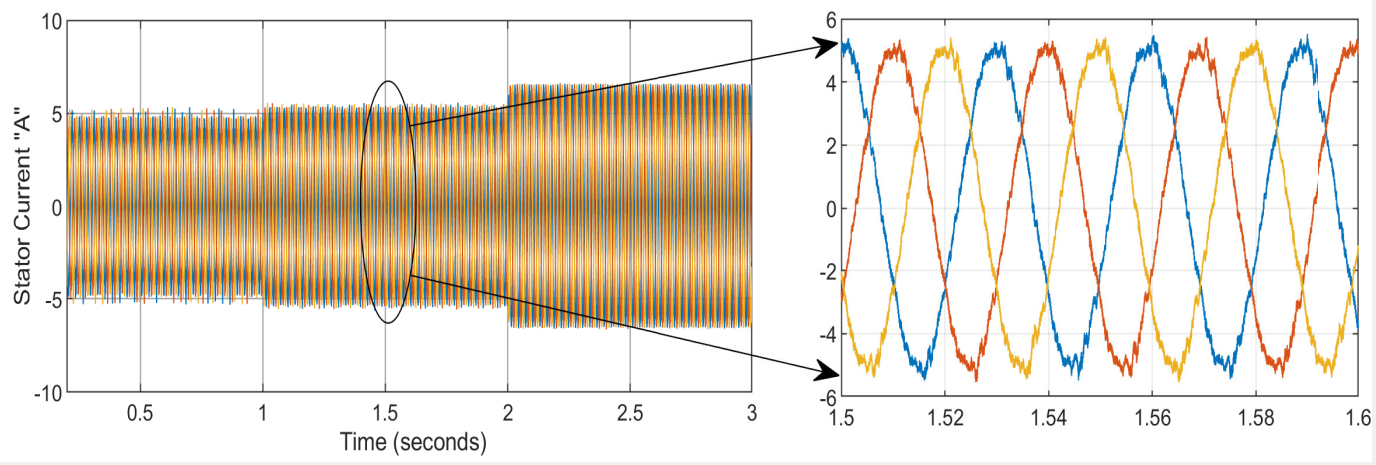

Figure 5. CDTC abc-stator currents

Figures 7(a) and 7(b) demonstrate the dynamic torque response for the two different methods. Initially, a load torque step change was applied from 0 to $8 \mathrm{Nm}$ with a reference speed command of $1000 \mathrm{r} / \mathrm{min}$ per $1 \mathrm{~s}$, then the load torque increases suddenly from 8 to $15 \mathrm{Nm}$ after another durable operation the speed was constant at $1000 \mathrm{r} / \mathrm{min}$. In the other hand, it can be observed that the torque ripples are decreased by using the suggested DTC-SVM based imaginary swapping instant. Figures 8 (a) and 8(b) the circular stator flux trajectory for the different methods. Figures 9(a) and 9(b) show the speed and flux responses for the studied control strategies.

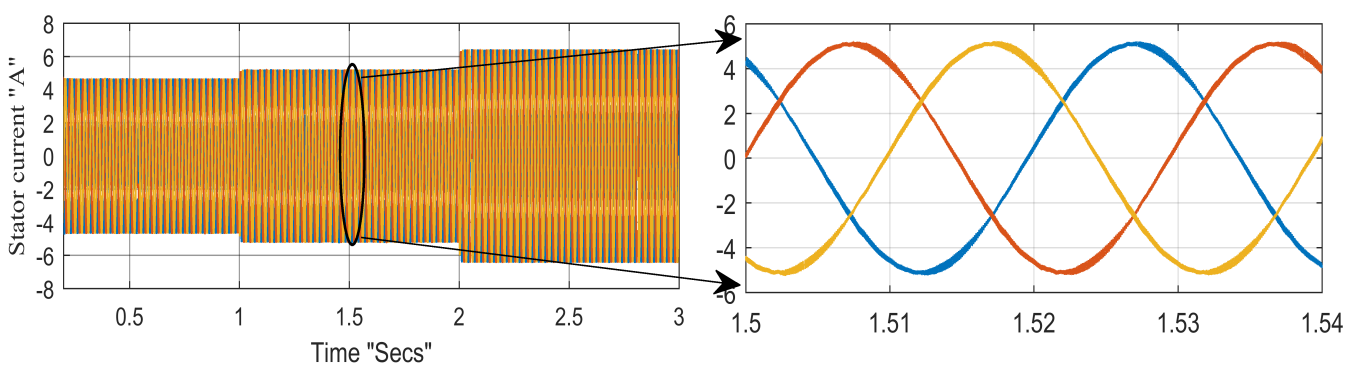

Figure 6. Improved DTC abc-stator currents

A comparative analysis is given in Table 2, which explicitly oppresses the dominance of the proposed strategy relative to the CDTC technique. The robustness of the proposed control strategy is tested and approved after creating some variation in the IM parameter's, and it's arising from skin effect or a weak identification of the IM. Thus, we multiplied the stator resistance and the motor inertia by two (Jm=200\% (Jmn) and Rs=200\% (Rsn)). The Figure 10 shows that the rotor speed follows its reference with a little impact on the response time due to the variance of IM parameter's. Also, the stator flux follows its circular trajectory as shown in Figure 11, which demonstrates that the suggested DTC-SVM ensure better outcomes in terms of robustness. 

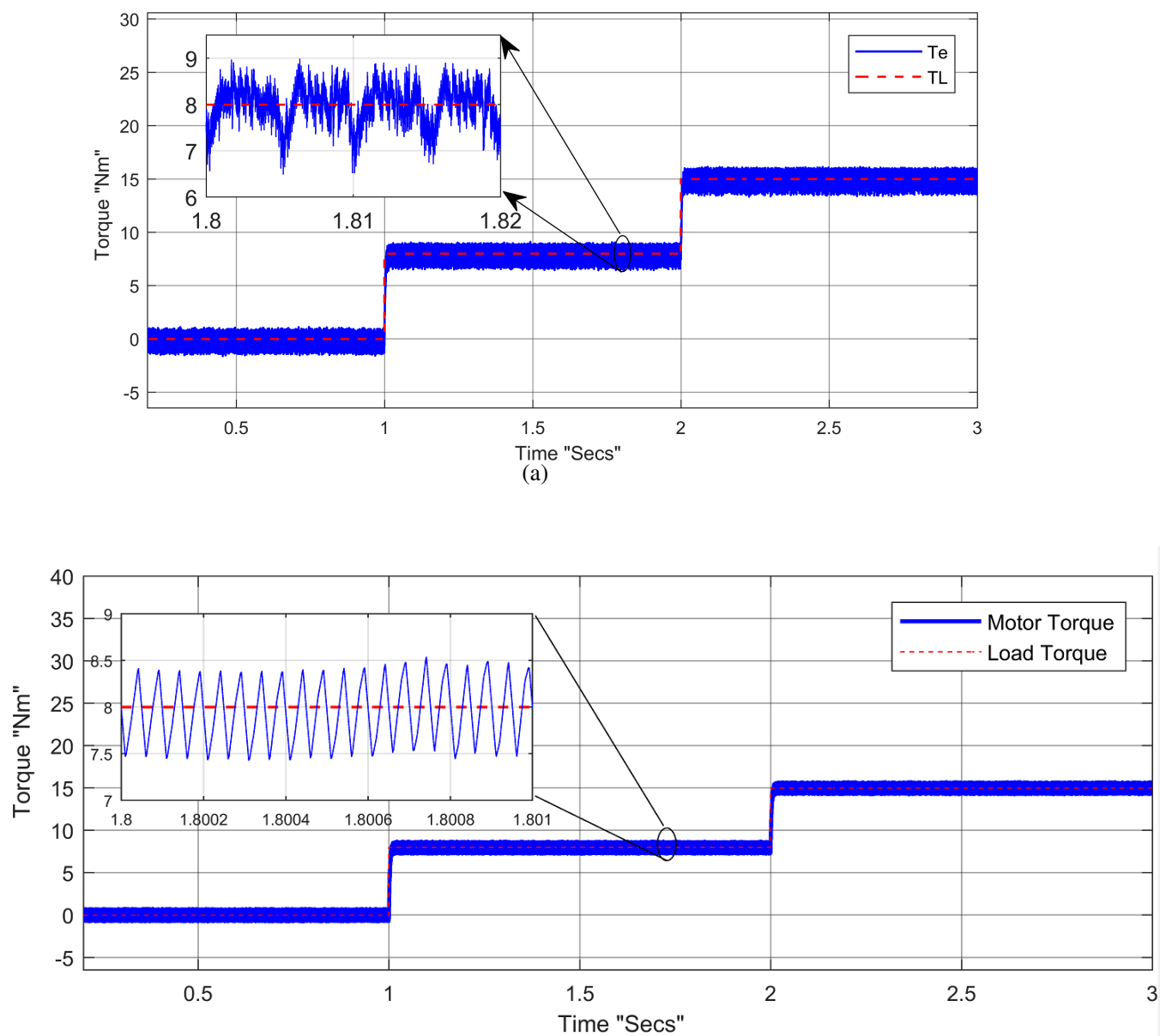

(b)

Figure 7. Dynamic torque response for two techniques, (a) CDTC electromagnetic torque and (b) electromagnetic torque of the improved technique

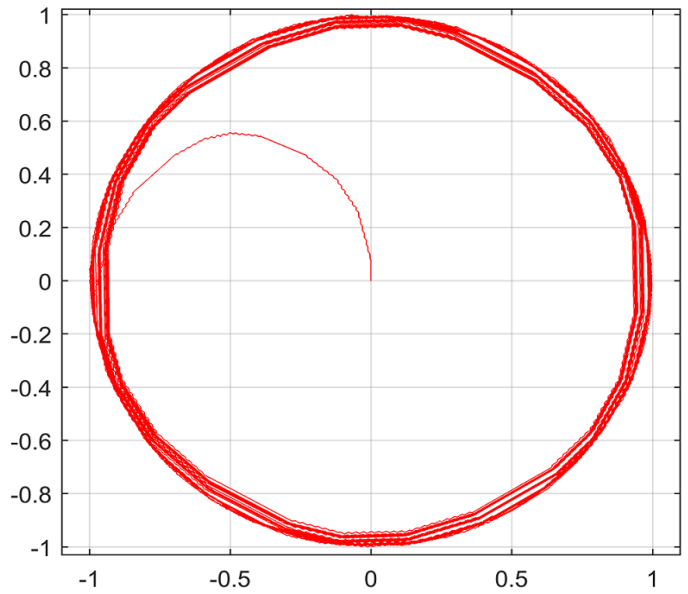

(a)

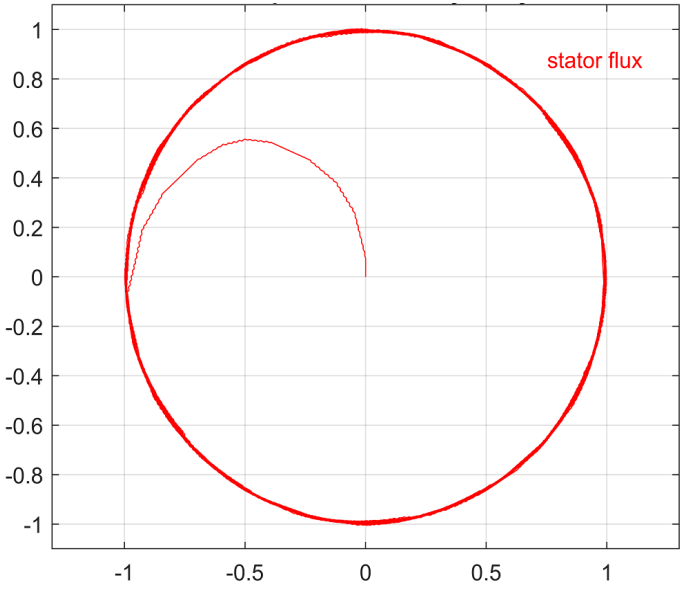

(b)

Figure 8. Stator flux trajectory of: (a) CDTC and (b) improved DTC-SVM technique 


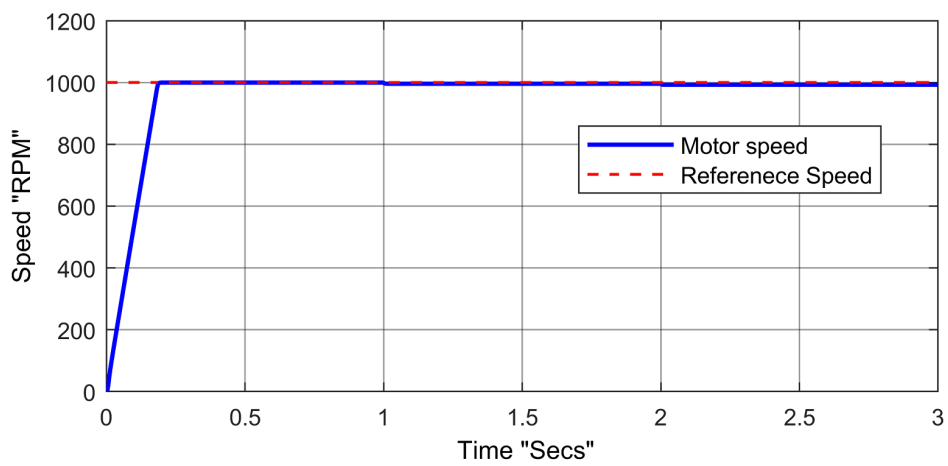

(a)

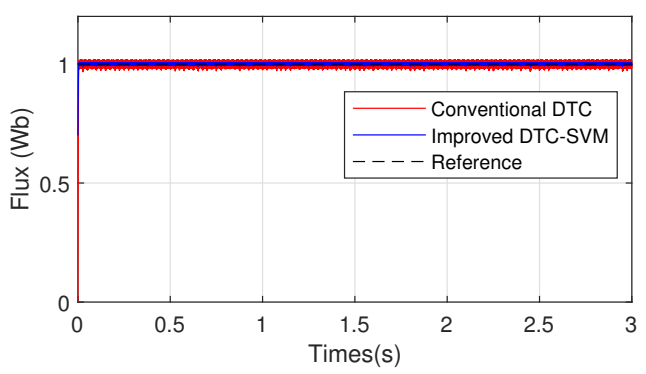

(b)

Figure 9. Simulation results of (a) speed response of the improved technique and (b) flux response of the studied techniques

Table 2. Performance and comparison analysis for the proposed technique

\begin{tabular}{ccccc}
\hline & Parameters & Classical-DTC & Proposed technique & Improv. Ratio(\%) \\
\hline \multirow{2}{*}{ Torque } & Ripples $(\mathrm{Nm})$ & 2.1 & 0.75 & 64.28 \\
& Response time $(\mathrm{s})$ & 0.533 & 0.254 & 52.34 \\
\multirow{3}{*}{ Speed } & Overshoot $(\mathrm{Rpm})$ & 31 & 8 & 74.19 \\
& Response time $(\mathrm{s})$ & 0.430 & 0.243 & 62.2 \\
Flux & Ripples(Wb) & 0.07 & 0.02 & 71.42 \\
\hline
\end{tabular}

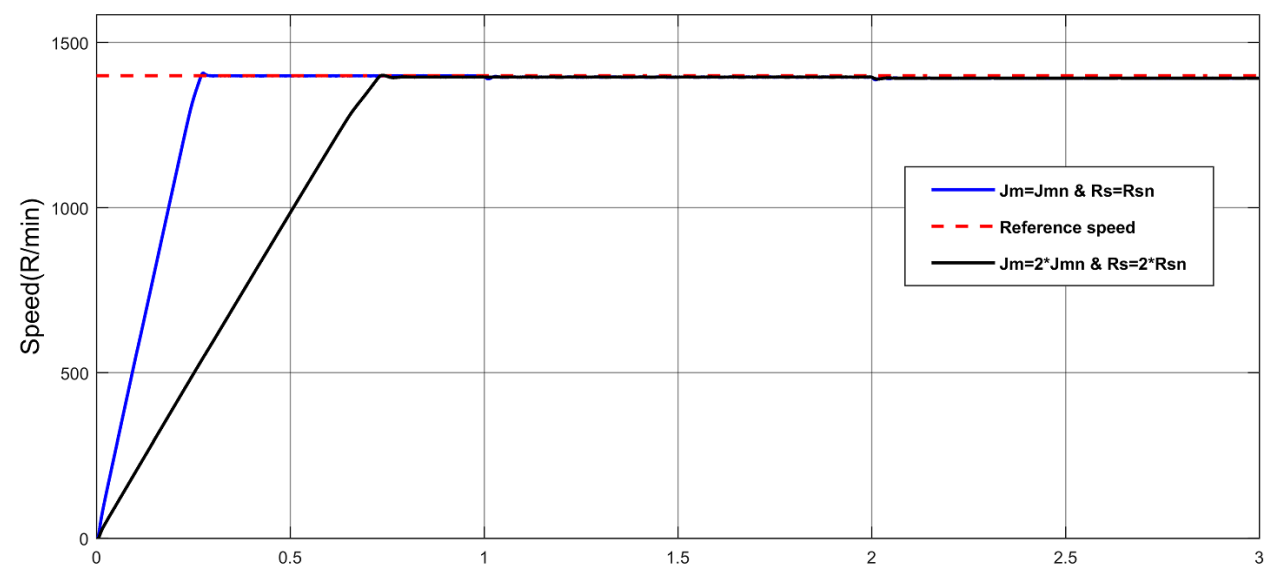

Figure 10. Speed response after the variation of IM parameters 


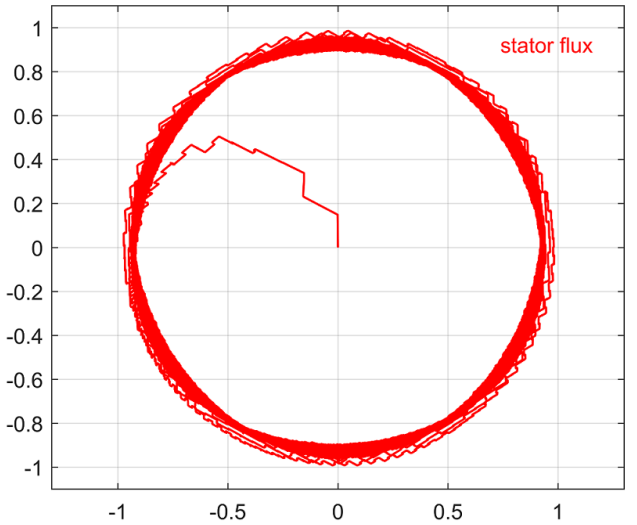

Figure 11. Flux trajectory after the variation of IM parameters

\section{CONCLUSION}

This paper presents an improved direct torque control applied to an induction machine, the enhanced technique excludes the calculation of the voltage vector; Also sector and angle determination is not required, which gives the processor more agility. On the one hand, in contrast with the CDTC, the suggested approach using DTC-SVM based imaginary swapping instant presents an excellent performance in terms of torque and flux ripples, in this sense, the torque and flux ripples are massively decreased by $64.28 \%$ and $71.42 \%$. In addition, it can also achieve a fast dynamic speed response as demonstrated in the simulation. On the other hand, this technique ensures better performance in terms of robustness against parameters and load's variation in low and high speed range. Therefore,the simulation results demonstrate that the proposed DTC-SVM technique is one of the best solutions to mitigate the limitations of the conventional DTC.

\section{REFERENCES}

[1] B. Singh, U. Sharma and S. Kumar "Standalone photovoltaic water pumping system using induction motor drive with reduced sensors," IEEE Transactions on Industry Applications, vol. 54, no. 4, pp. 3645-3655, 2018, doi: 10.1109/TIA.2018.2825285.

[2] A. A. Kadum, "New adaptive hysteresis band width control for direct torque control of induction machine drives," International Journal of Power Electronics and Drive Systems (IJPEDS), vol. 11, no. 4, pp. 1908-1917, 2020, doi: 10.11591/ijpeds.v11.i4.pp1908-1917.

[3] K. B. Lee and F. Blaabjerg, "Improved direct torque control for sensorless matrix converter drives with constant switching frequency and torque ripple reduction," International Journal of Control, Automation and Systems, vol. 4, no. 1, pp. 113-123, 2006, doi :10.1080/00207170500490455

[4] T. Poompavai and M. Kowsalya, "Control and energy management strategies applied for solar photovoltaic and wind energy fed water pumping system: A review," Renewable and Sustainable Energy Reviews, vol. 107, pp. 108-122, 2019, doi: 10.1016/j.rser.2019.02.023.

[5] I. Takahashi and T. Noguchi, "A new quick-response and high-efficiency control strategy of an induction motor," IEEE Transactions on Industry Applications, vol. IA-22, no. 5, pp. 820-827, 1986, doi: 10.1109/TIA.1986.4504799.

[6] I. Takahashi and Y. Ohmori, "High-performance direct torque control of an induction motor," IEEE Transactions on Industry Applications, vol. 25, no. 2, pp. 257-264, 1989, doi: 10.1109/28.25540.

[7] S. Jacques, "Modeling and Implementation of the direct torque control technique used in a relevant pv-powered pumping," Journal of Electrical Engineering, vol. 18, no. 2, pp. 10-10, 2019.

[8] A. Ammar, A. Benakcha, and A. Bourek, "Closed loop torque SVM-DTC based on robust super twisting speed controller for induction motor drive with efficiency optimization," International Journal of Hydrogen Energy, vol. 42, no. 28, pp. 17940-17952, 2017, doi: 10.1016/j.ijhydene.2017.04.034.

[9] A. Ouarda, B. El Badsi, and A. Masmoudi, "Bus-Bus-clamping-based direct torque control strategy dedicated to B6-inverter fed symmetrical two-phase IM drive," IEEE Transactions on Industrial Electronics, vol. 65, no. 7, pp. 5344-5352, 2018, doi: 10.1109/TIE.2017.2777384.

[10] S. S. Letha, T. Thakur, and J. Kumar, "Harmonic elimination of a photo-voltaic based cascaded H-bridge multilevel inverter using PSO (particle swarm optimization) for induction motor drive," Energy, vol. 107, pp. 335-346, 2016, doi: 10.1016/j.energy.2016.04.033.

[11] S. A. A. Tarusan, A. Jidin, and Mohd Luqman M. Jamil, "The simulation analysis of torque ripple reduction by using 
optimal voltage vector in DTC fed by five-level CHB inverter," Indonesian Journal of Electrical Engineering and Computer Science (IJEECS), vol. 20, no. 3, pp. 1665-1676, 2020, doi: 10.11591/ijeecs.v20.i3.pp1665-1676.

[12] S. S. Yi et al., "Loss minimization DTC electric motor drive system based on adaptive ANN strategy," International Journal of Power Electronics and Drive Systems (IJPEDS), vol. 11, no. 2, pp. 618-624, 2020, doi: 10.11591/ijpeds.v11.i2.pp618-624.

[13] W. M. Utomo et al., "Speed tracking of field oriented control permanent magnet synchronous motor using neural network," International Journal of Power Electronics and Drive Systems (IJPEDS), vol. 4, no. 3, pp. 290-298, 2014, doi: 10.11591/ijpeds.v4i3.5941.

[14] D. K. Kumar, and G. T. Ram Das, "Adaptive fuzzy controller based self regulated reference stator flux estimator of direct torque control for three level inverter fed IPMSM," International Journal of Intelligent Engineering and Systems, vol. 13, no. 2, pp. 11-19, 2020, doi: 10.22266/ijies2020.0430.02.

[15] H. Guzman, F. Barrero, and M. J. Duran, "IGBT-gating failure effect on a fault-tolerant predictive current controlled 5-phase induction motor drive," IEEE Transactions on Industrial Electronics, vol. 62, no. 1, pp. 15-20, 2014, doi:10.1109/TIE.2014.2331019.

[16] H. Guzman et al., "Comparative study of predictive and resonant controllers in fault-tolerant five-phase induction motor drives," IEEE Transactions on Industrial Electronics, vol. 63, no. 1, pp. 606-617, 2016, doi:10.1109/TIE.2015.2418732.

[17] H. Hamidane, S. El Faiz, M. Guerbaoui, A. Ed-Dahhak, A. Lachhab, and B. Bouchikhi, "Constrained discrete model predictive control of a greenhouse system temperature," International Journal of Electrical and Computer Engineering (IJECE), vol. 11, no. 2, pp. 1223-1234, 2021, doi: 10.11591/ijece.v11i2.pp1223-1234.

[18] J. Zhang and M. F. Rahman, "Analysis and design of a novel direct flux control scheme for induction machine," 2005 IEEE International Conference on Electric Machines and Drives, no. 8, 2005, pp. 426-430, doi: 10.1109/iemdc.2005.195758.

[19] A. Selmani, A. Ed-Dahhak, M. Outanoute, A. Lachhab, M. Guerbaoui, and B. Bouchikhi, "Performance evaluation of modelling and simulation of lead acid batteries for photovoltaic applications," International Journal of Power Electronics and Drive Systems (IJPEDS), vol. 7, no. 2, pp. 472-480, 2016, doi:10.11591/ijpeds.v7.i2.pp472-480.

[20] B. Manale, B. Badre, A. A. Hala, T. Mohammed, L. Ahmed and L. Petru, "DEADBEAT control applied toWind power system," 5th International Conference on Renewable Energies for Developing Countries (REDEC), 2020, pp. 1-5, doi:10.1109/REDEC49234.2020.9163601.

[21] R. Tabasian, M. Ghanbari, A. Esmaeli and M. Jannati, "A novel speed control strategy for 3-phase induction motor drives with star-connected under single-phase open-circuit fault using modified RFOC strategy," ISA Transactions, 2021, doi:10.1016/j.isatra.2021.06.011.

[22] R. Abdelli, D. Rekioua, T. Rekioua and A. Tounzi, "Improved direct torque control of an induction generator used in a wind conversion system connected to the grid," ISA Transactions, vol. 52, no. 4, pp. 525-538, 2013, doi: 10.1016/j.isatra.2013.03.001.

[23] A. Ammar, A. Bourek, and A. Benakcha, "Modified load angle direct torque control for sensorless induction motor using sliding mode flux observer," 2015 4th International Conference on Electrical Engineering, ICEE 2015, no. 5, 2016, pp. 1-6, doi: 10.1109/INTEE.2015.7416602.

[24] H. A. Aroussi, E. Ziani, M. Bouderbala, and B. Bossoufi, "Improvement of direct torque control applied to doubly fed induction motor under variable speed," International Journal of Power Electronics and Drive Systems (IJPEDS, vol. 11, no. 1, pp. 97-106, 2020, doi: 10.11591/ijpeds.v11.i1.pp97-106.

[25] G. H. B. Foo, and X. Zhang, "Constant switching frequency based direct torque control of interior permanent magnet synchronous motors with reduced ripples and fast torque dynamics," IEEE Transactions on Power Electronics, vol. 31, no. 9, pp. 6485-6493, 2016, doi: 10.1109/TPEL.2015.2503292.

[26] D. W. Chung, J. S. Kim, and S. K. Sul, "Unified voltage modulation technique for real-time three-phase power conversion," IEEE Transactions on Industry Applications, vol. 34, no. 2, pp. 374-380, 1998, doi: 10.1109/28.663482.

\section{BIOGRAPHIES OF AUTHORS}

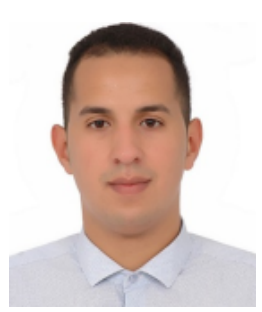

Iliass Rkik (i) 5 is 5 is a Ph. D. student in Electrical Engineering and member of the System's Modeling, Materials, and Control group at Laboratory of Computer Engineering and Intelligent Electric Systems from Ecole Superieure de Technologie, Meknes, Moulay Ismail University, Morocco. He received his Master degree in Electronics Engineering from the Faculty of Science in Fez. His research studies include control strategies of power converters, electrical machines drives, renewable energy and power electronics. He could be contacted via email: rkik.iliass@ gmail.com. 


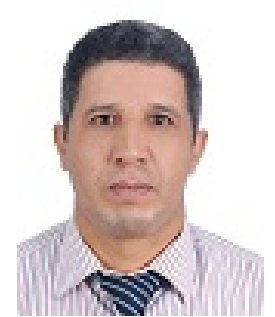

Mohamed El khayat (D) IS $5 \mathbb{P}$ is an aggregate teacher in electrical engineering, a current PH.D. student, part of the System's Modeling, Materials, and Control group at Laboratory of Computer Engineering and Intelligent Electric Systems from Ecole Superieure de Technologie, Meknes, Moulay Ismail University, Morocco. He received the D.E.S.A. degree in electric energy from Mohamedia school of Engineering, Mohamed 5 university Rabat Morocco. His research studies are focused on renewable energy and power electronics. He could be contacted via email: elkhayat.med@ gmail.com.

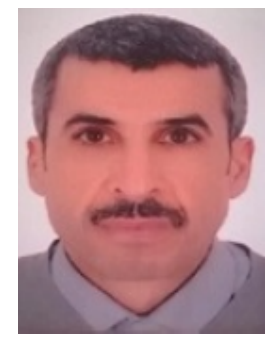

Abdelali Ed-Dahhak (D) 5 is P is a Professor at Ecole Superieure de Technologie, Meknes, Moulay Ismail University, Morocco. Member of the System's Modeling, Materials, and Control group at Laboratory of Computer Engineering and Intelligent Electric Systems. He earned the Ph.D. degree in 2009, from Faculty-of-Sciences, Meknes. His area of research interests are electronics, electrical machine drives, the development of a climate monitoring system and the management of greenhouse drip irrigation. He could be contacted via email: a.eddahhak@est-umi.ac.ma.

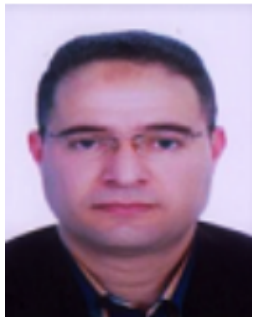

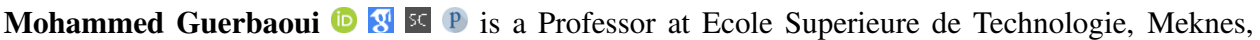
Moulay Ismail University, Morocco. Member of the System's Modeling, Materials, and Control group at Laboratory of Computer Engineering and Intelligent Electric Systems. He earned the Ph.D. degree in 2014, from Faculty-of-Sciences, Meknes. His area of research interests are mainly focussed on power quality, electrical drives, fuzzy logic control techniques for greenhouse drip irrigation. He could be contacted via email: guerbaoui@gmail.com.

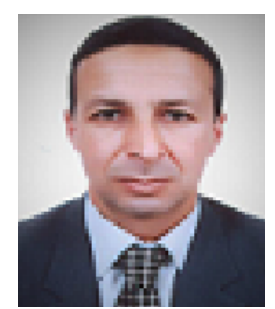

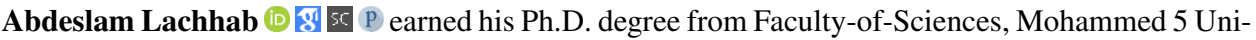
versity in 2000. He is a Professor of Electrical Engineering and the head of Laboratory of Computer Engineering and Intelligent Electric Systems in the Higher School of Technology, Moulay Ismail University, Meknes, Morocco. his area of research interests focuses on modelling and automatic control of electrical drives, he could be contacted via email: abd_lachhab@yahoo.fr. 